\title{
Remoção de professores e desigualdades em territórios vulneráveis ${ }^{1}$
}

\author{
Luciana Alves* \\ Frederica Padilha** \\ Antônio Augusto Gomes Batista*** \\ Maurício Érnica**** \\ Hamilton Harley de Carvalho-Silva*****
}

*Mestre pela Faculdade de Educação da USP (FEUSP) e professora e coordenadora pedagógica de ensino superior no Instituto Sumaré de Ensino Superior luciana_lualves@yahoo.com.br

**Mestre pela Université Paris Dauphine em Economia Internacional e Desenvolvimento frepadilha@hotmail.com

*** Coordenador da Coordenação de Desenvolvimento de Pesquisas do Centro de Estudos e Pesquisas em Educação, Cultura e Ação Comunitária (Cenpec). Foi professor da Faculdade de Educação da Universidade Federal de Minas Gerais (UFMG) e de seu Programa de Pós-Graduação entre 1990 e 2014 antonio.batista@cenpec.org.br

$\star \star \star \star *$ Professor da Faculdade de Educação da Universidade Estadual de Campinas (Unicamp) mauernica@gmail.com

$\star \star \star \star \star *$ Mestre e doutorando em Educação pela FEUSP e professor do Instituto Federal de São Paulo hamilton.harley@gmail.com
Resumo: Este artigo investiga um dos mecanismos pelos quais desigualdades socioespaciais interferem no funcionamento de escolas que se situam em territórios vulneráveis, no caso sobre a alocação de professores em escolas municipais na subprefeitura de São Miguel Paulista (SMP). Para verificar a hipótese de se em São Paulo o padrão de migração dos docentes se dá em direção a escolas de bairros menos vulneráveis e com público de maiores recursos sociais e culturais, analisamos dados dos concursos de remoção de 2006 a 2011 de professores que atuam nos anos iniciais do ensino fundamental, disponíveis no Diário Oficial da Cidade de São Paulo. Os resultados apontam que as escolas de entorno menos vulnerável e que concentram alunos com maiores recursos atraem professores que ocupam as melhores posições na carreira. As escolas de perfil oposto recebem os docentes com menores classificações nos concursos.

Palavras-chave: Remoção de professores. Vulnerabilidade social. Território.

1 A pesquisa da qual este artigo faz parte contou com financiamento das seguintes instituições: Fundo de Pesquisa Educação para o Século XXI, Fundação de Amparo à Pesquisa do Estado de São Paulo (Fapesp), Fundação Tide Setubal, Fundação Itaú Social e Fundo das Nações Unidas para a Infância (Unicef). 
INTRODUÇÃO

Em 2009, iniciamos pesquisa que visava analisar se e como diferenças entre as regiões urbanas em termos de infraestrutura, locomoção, reputação do local e outras características que indicam desigualdades socioespaciais impactavam a educação ofertada por escolas públicas. As conclusões da investigação indicaram que estabelecimentos de ensino situados em regiões de alta vulnerabilidade social apresentavam maiores dificuldades para efetivar seus projetos educacionais devido à influência de diversos fatores ligados a desigualdades socioespaciais (ÉRNICA; BATISTA, 2012). Entre esses fatores, alguns permitiram elaborar a hipótese de que as boas condições de funcionamento de um estabelecimento de ensino estavam relacionadas às dificuldades vividas por outros estabelecimentos, o que indicava a existência de relações de interdependência entre escolas. Os dados sugeriram, ainda, que as escolas situadas em territórios mais vulneráveis enfrentariam mais dificuldades para garantir um bom funcionamento.

O estudo de caráter exploratório aqui apresentado busca avançar no exame dessa hipótese a partir da análise de dados de concursos de remoção de professores. 0 objetivo central é verificar se as desigualdades socioespaciais e a composição sociocultural dos alunos interferem na alocação de docentes nas escolas por meio dos concursos de remoção.

Os resultados apontam que a vulnerabilidade do território em que está situada a escola e a composição sociocultural do corpo discente - que, no caso de São Paulo, é resultante da setorização da matrícula e das desigualdades socioespaciais expressas principalmente pela alocação residencial da população - influenciam a mobilidade dos professores. Algumas evidências empíricas permitiram-nos chegar a estas conclusões:

Nas trocas de professores entre São Miguel Paulista (SMP) e a cidade de São Paulo, a subprefeitura está em desvantagem, pois a maioria dos ingressantes está entre os com classificação mais baixa nos concursos de remoção.

Os docentes que ocupam as melhores posições na carreira (os que obtiveram as melhores classificações no concurso) quando entram na subprefeitura, escolhem, em sua maioria, escolas de entorno menos vulnerável e que concentram alunos com maiores recursos culturais.

Nas trocas de escolas dentro do território estudado, a maioria dos docentes que trabalhava em estabelecimentos de ensino com entorno mais vulnerável 
e com alunos de recursos socioculturais baixos ou heterogêneos migrou para escolas de vizinhança menos vulnerável e com estudantes de mais altos recursos socioculturais.

Além dessas evidências, que sugerem a existência de relações entre hierarquias socioespaciais e a interdependência entre estabelecimentos de ensino mediadas pela concorrência de professores por escolas, o estudo nos levou à formulação de uma nova hipótese diretamente relacionada à carreira do magistério, bem como à retomada da conclusão da pesquisa que deu origem à investigação: em sistemas de ensino nos quais a possibilidade de transferência do professor de uma escola está ligada ao seu capital profissional, acumular capital e obter melhor classificação nos concursos de remoção possibilita um avanço positivo na hierarquia socioespacial ou, em outros termos, aquilo a que Becker (1952) chama de progressão horizontal na carreira.

Para discutir essa hipótese, bem como as conclusões, o texto está dividido em três seções. A primeira apresenta as bases teóricas que utilizamos para formular o problema investigado. A segunda discute as regras do concurso de remoção, que permitem analisar como, no contexto pesquisado, se forma o capital profissional a partir do qual docentes concorrem entre si por escolas de sua preferência. A última parte apresenta a metodologia e discute os achados empíricos da pesquisa.

\section{REMOÇÃO E ASCENSÃO HORIZONTAL NA CARREIRA DOCENTE}

Becker (1952) foi um dos primeiros a estudar o trânsito de professores entre escolas, em Chicago. Segundo ele, a possibilidade de transferência de cargo para outras regiões da cidade evidencia um eixo horizontal de ascensão na carreira do magistério que permite distinguir os postos de trabalho que ocupam uma mesma posição hierárquica e que, do ponto de vista formal, seriam iguais, mas que apresentam prestígio diferenciado em função da forma e da intensidade com que os problemas básicos do trabalho docente ocorrem nas escolas. Nesse eixo, os professores buscariam locais para trabalhar onde os problemas da carreira são menos intensos e mais suscetíveis de solução.

Esses problemas decorreriam das relações que os professores estabelecem com seus colegas, diretores, pais e alunos e os mais difíceis seriam aqueles relacionados aos últimos (BECKER, 1952). A partir de 60 entrevistas, o autor identifica três classes sociais de alunos no discurso dos docentes (baixa, 
média e alta) e três grupos de problemas que assumiriam configurações diferentes segundo cada classe social. Os problemas mais usuais seriam relativos ao ensino, incidindo sobre conhecimentos e capacidades necessários ao prosseguimento dos estudos; relativos à disciplina, entendida como o controle do docente sobre as atividades dos alunos; e os relativos à aceitação moral dos comportamentos dos alunos pelos professores.

Para os professores de Chicago, as crianças da classe mais baixa seriam difíceis de ensinar, indisciplinas "e moralmente inaceitáveis em todos os níveis, da higiene física às esferas do sexo e da "ambição para subir na vida"” (BECKER, 1952, p. 472). A movimentação horizontal na carreira, portanto, tenderia a se dirigir dos bairros pobres com forte presença da população negra (os "slums") para as "melhores vizinhanças" e aos bairros pobres se dirigiriam os docentes em início de carreira.

O mecanismo de mobilidade horizontal apontado pelo autor chegava a desestimular a mobilidade vertical, obtida, por exemplo, por meio de exames para o cargo de diretor de escola. Um professor "bem situado" no eixo horizontal da carreira, isto é, do ponto de vista da localidade e da composição sociocultural discente, se fosse aprovado em um concurso para direção, poderia ter de assumir uma escola nos bairros pobres, regredindo, assim, nesse eixo da carreira.

Para Becker, a ascensão horizontal na carreira tem dois eixos associados: o socioespacial, que diz respeito à localização da escola; e o intraescolar, relativo à composição sociocultural discente. Trata-se de dois elementos a serem considerados pelos docentes, pois se fosse ponderada apenas a localização, o professor poderia fazer escolhas equivocadas, como escolher uma escola com alunos de classe baixa de bairro de classe social alta.

Torres et al. (2008), de outro ponto de vista, também abordam essa questão e analisam as desigualdades educacionais nas escolas públicas da cidade de São Paulo considerando diferenças entre as que se localizam no centro e na periferia. Eles argumentam que, mesmo após o controle estatístico de variáveis individuais tradicionalmente associadas às desigualdades escolares (renda familiar, escolaridade dos pais, sexo, raça), persistem desigualdades educacionais entre indivíduos com características sociais similares, porém residentes em regiões diferentes da cidade. Eles investigam como são produzidas essas desigualdades e dedicam-se à análise de mecanismos relativos à oferta educacional, buscando compreender até que ponto as instituições e as políticas educacionais contribuem, ou não, para sua produção. 
Torres et al. (2008) identificam mecanismos relacionados ao tempo de permanência dos alunos nas escolas, à posição dos docentes na carreira e à percepção dos professores sobre os alunos. São os dois últimos que mais nos interessam. 0 estudo chegou a três conclusões sobre o perfil da pontuação dos docentes na carreira em função da localização das escolas em regiões periféricas e centrais, a partir de entrevistas semiestruturadas. A primeira delas é que "o conjunto de normas relativas à alocação de profissionais no sistema estadual e municipal direciona para escolas de periferia professores com baixa pontuação em concurso público e/ou profissionais recémingressados no sistema público" (TORRES et al., 2008, p. 76).

A segunda conclusão é que há maior incidência de professores substitutos e temporários nas escolas periféricas. A terceira conclusão é que em lugares periféricos "a rotatividade é muito maior. Tem rotatividade de direção, de professor. Em escola de periferia, o cara não para mesmo, ingressou lá e depois está fora, então não dá para ter um trabalho contínuo", afirmou um coordenador de escola estadual (TORRES et al., 2008, p. 77).

Quanto à percepção docente sobre os alunos, os autores identificam apreciações valorativas negativas sobre os estudantes oriundos de famílias pobres. Eles seriam mais interessados nos benefícios ofertados pela escola (alimentação, sobretudo) do que na educação escolar e careceriam de higiene e de hábitos sociais e valores estimados pela escola. Os professores têm também baixas expectativas em relação ao futuro de tais alunos (TORRES et al., 2008).

Os estudos de Becker (1952) e Torres et al. (2008) revelam a existência de escolas que têm pouco prestígio entre os professores e que têm maiores dificuldades para atrair e manter seu corpo docente. Quando a alocação desses profissionais fica sujeita a suas escolhas pessoais, cotejadas pelas escolhas dos demais professores na competição pela transferência de escola, algumas unidades escolares têm que lidar com altos índices de rotatividade de professores.

Rotatividade designa o processo em que empregados se transferem dentro e entre organizações ou deixam o mercado de trabalho. Esse processo pode ser originado pelo trabalhador (rotatividade voluntária) ou originado pelo empregador (rotatividade involuntária) e ainda pode ser interno ou externo. A rotatividade interna diz respeito a mudanças de postos de trabalho dentro da organização - em nosso contexto, seria o caso de um professor da rede municipal que muda de uma escola para outra da mesma rede por meio de remoção, por exemplo. A rotatividade externa ocorre quando o empregado 
sai da organização, seja para trabalhar em outra instituição ou para deixar a profissão (KASMIRSKI, 2012).

A alta rotatividade pode prejudicar a qualidade do ensino da escola, indicada pela possibilidade de diminuição do desempenho dos alunos em testes padronizados. Biondi e Felício (2007) verificaram que a rotatividade de

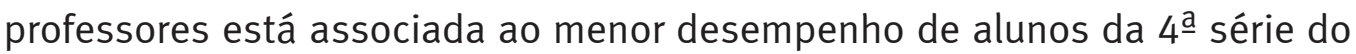
ensino fundamental (EF) na prova de matemática do Sistema de Avaliação da Educação Básica (Saeb). Ronfeldt et al. (2011) mostram que a rotatividade docente reduziu o desempenho em matemática e inglês de estudantes da $4^{\underline{a}}$ e $5^{\underline{a}}$ séries de escolas elementares de Nova York na década de 2000 e ainda que a rotatividade mostrou-se particularmente prejudicial em escolas com maior proporção de alunos de baixo desempenho acadêmico e negros.

Kasmirski (2012) evidencia que a rotatividade interna é responsável por grande parte da rotatividade desses profissionais na rede estadual de São Paulo, afetando especialmente as escolas que concentram alunos com menor nível socioeconômico e negros². A análise dos padrões de remoção nesses estudos revela a existência de uma distribuição desigual de recursos humanos essenciais para o processo educacional de qualidade nas escolas, que se apoia nas desigualdades socioespaciais e socioculturais, tal como apontado por Becker.

Obviamente as escolhas dos professores não refletem apenas os padrões sociais de diferenciação pautados na classe social, raça e território, mas também ocorrem em função de outros fatores, mais diretamente ligados à dinâmica escolar, como o gerenciamento de problemas de disciplina, os modelos de gestão e os recursos disponíveis; ou a fatores de política educacional como aqueles ligados à diferenciação salarial (HANUSHEK et al., 2004). Isso implica que os condicionantes da mobilidade docente são muito mais abrangentes do que aqueles que puderam ser tratados ao longo do presente texto.

De modo semelhante, o fato de um docente permanecer numa mesma escola não significa que seu empenho na efetivação de suas atividades se dê independentemente do perfil da instituição. A esse respeito, Agnès Van Zanten e Marie-France Grospiron (2001), identificam três lógicas de construção da carreira docente nos estabelecimentos "difíceis", sendo uma

2 Uma ampla busca realizada no Portal Capes mostrou que foram raras as investigações nacionais e de relevância que associassem transferência de docentes à dimensão socioespacial. 
delas o desengajamento em relação à atividade profissional, o que pode se dar pelo absenteísmo e pelo uso de expedientes legais, como licenças, estágios de formação, licença-saúde, entre outros. As demais estratégias seriam a ascensão vertical (ocupação de postos fora da docência) e a ascensão socioespacial (horizontal).

\section{A Remoção na Rede municipal de SÃo Paulo}

Os professores efetivos que desejam transferir-se de escola podem participar dos concursos de remoção (SÃO PAULO, 1992). Nesses concursos, os interessados indicam as unidades escolares para as quais desejam "remover" seu cargo e, caso consigam, iniciam suas atividades no ano letivo subsequente num novo estabelecimento de ensino. Os candidatos concorrem entre si a partir de uma classificação estabelecida pela combinação entre tempo de magistério e títulos, por uma vaga na escola pleiteada (SÃO PAULO, 2008) ${ }^{3}$.

As regras do concurso definem as formas como a pontuação será calculada e os candidatos, classificados. Em 2011, por exemplo, para o cálculo da pontuação por tempo, para cada mês de efetivo exercício na docência foi atribuída uma pontuação que variava entre 0,2 e 0,4 ponto, a depender do cargo ocupado. A formação acadêmica também é pontuada. Para cada diploma ou certificado, é atribuído um valor entre, no máximo, 7,0 pontos (para o curso de doutorado em Educação ou Ciências Humanas e Sociais) a, no mínimo, 0,1 ponto - para a participação em eventos educacionais com duração mínima de dez horas (SÃO PAULO, 2011).

Esses critérios são verificados em outros contextos latino-americanos (MORDUCHOWICZ, 2003) e indicam as possibilidades de ascensão na carreira a partir da combinação de antiguidade no cargo e aperfeiçoamento profissional. Essa ascensão, além de ser revertida em melhoria salarial, também garante aos professores a preferência na escolha de turmas quando da atribuição de classes. Ou seja, quanto maior seu capital profissional, maior a pontuação do professor, e maiores as chances de que ele ocupe vagas mais prestigiadas nas hierarquias escolares, sejam elas intraescolares ou socioespaciais.

3 Outra forma de transferir-se de escola é a permuta, onde dois candidatos trocam entre si as vagas que estão ocupando, sem haver a necessidade de concorrência com os demais professores. As permutas podem ocorrer no mês de janeiro e, excepcionalmente, no mês de julho (SÃO PAULO, 1992). 
Neste trabalho, capital profissional designa os recursos de que dispõem os professores paulistanos para obterem posições na carreira nos momentos em que concorrem entre si (tempo de serviço e títulos). Porém, não temos elementos para afirmar que, em nosso contexto, quanto maior o capital profissional de um professor, melhor é o desempenho de seus alunos. Geralmente, o efeito da qualidade do professor sobre resultados dos alunos é medido pelo efeito de características específicas como a escolaridade e a experiência. Hanushek e Rivkin (2006) fizeram um levantamento sobre a relação entre proficiência dos alunos e escolaridade e experiência docente nos Estados Unidos e constataram que, na maioria dos artigos, essas duas variáveis não se relacionam com o desempenho dos estudantes. Acredita-se que o efeito da experiência seja não linear, de modo que as regressões lineares comumente estimadas não o captam. Os autores apresentam evidências de que o efeito da experiência sobre a qualidade da instrução se concentra nos primeiros anos da carreira. Nos países em desenvolvimento o cenário é um pouco diferente, pois há mais evidências de que educação e anos de docência aumentam a qualidade da instrução, mas, por outro lado, os modelos quase sempre têm variáveis importantes omitidas. Hanushek et al. (2005) afirmam que para identificar o efeito da qualidade docente sobre desempenho discente é necessário controlar variáveis como a história familiar dos alunos, o efeito de pares, de vizinhança, bem como outros fatores relacionados à própria escola.

As remoções podem ser voluntárias ou compulsórias. Estas ocorrem quando a escola é extinta, quando seu número de classes ou aulas diminui e quando o docente efetivo está lotado em vaga precária (SÃO PAULO, 2008, 2007). Para a interpretação dos dados sobre os concursos é importante investigar se a maioria das mudanças de escolas ocorre por iniciativa do professor ou não, pois no primeiro caso os resultados encontrados expressariam preferências docentes quanto aos postos de trabalho e no segundo expressariam uma combinação entre preferências dos professores, da Secretaria (de certo modo explicitadas na legislação) e de situações fora do controle de ambas as partes (como variações da matrícula).

Para investigar se podemos considerar a maioria das remoções como de ofício ou voluntárias, observamos os dados de matrícula das escolas da região de 2007 a 2011 (Figura 1). Percebe-se que houve uma redução de 25\% nas matrículas, indicando uma possível queda no número de turmas dessas escolas. Isto pode ter obrigado uma parcela dos docentes a se remover. 


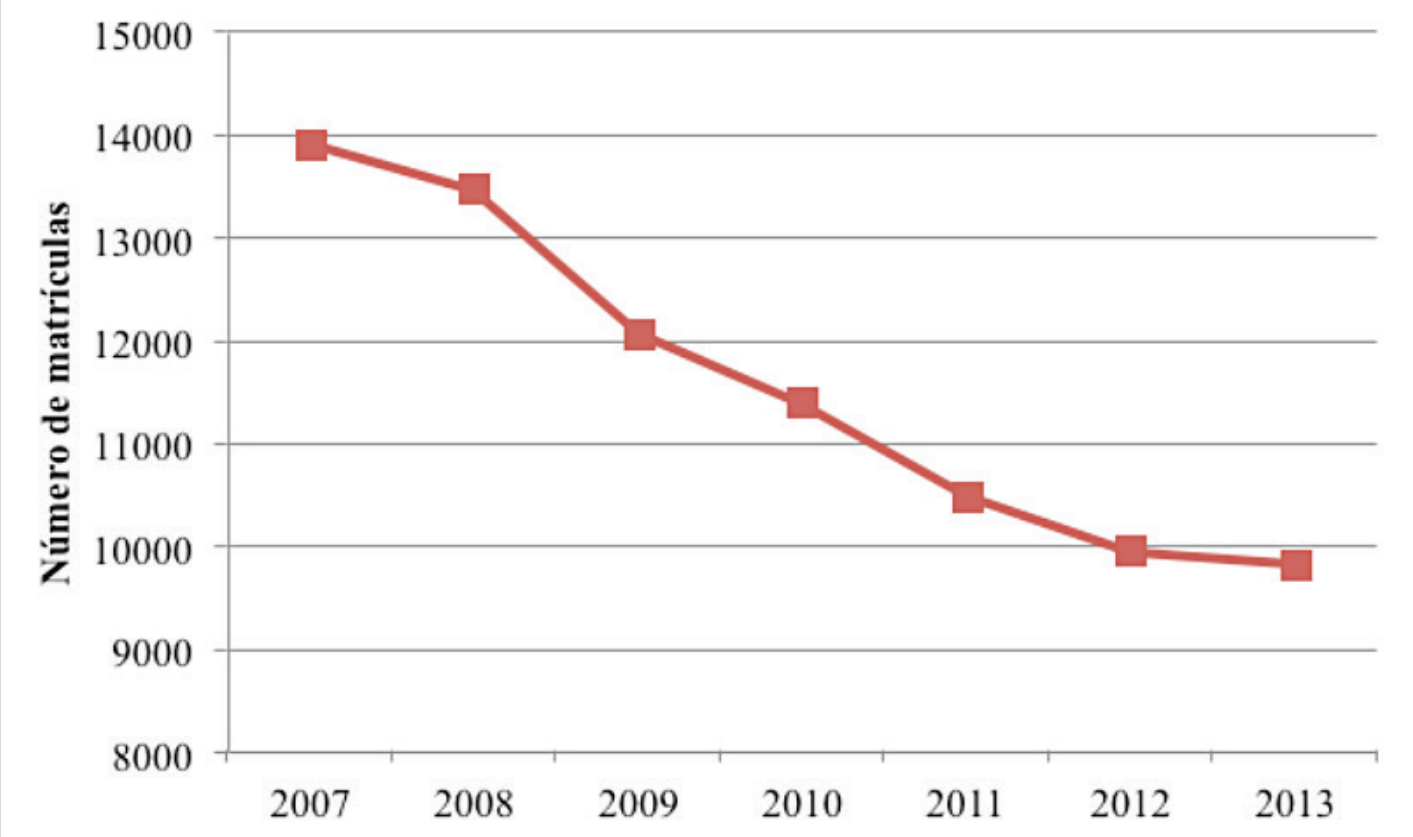

Figura 1: Número de matrículas nas escolas da subprefeitura de São Miguel Paulista.

Fonte: Censo Escolar/Inep.

Os docentes que são considerados excedentes e que são obrigados a migrar estão em posição inferior na carreira, pois “sobraram” na atribuição de turmas e, se fossem participar do concurso de remoção apenas com o capital profissional que acumularam, estariam sujeitos às vagas menos prestigiadas. Por outro lado, como sua participação no concurso foi compulsória, eles têm prioridade de escolha. Esses docentes são classificados seguindo as mesmas regras anteriormente descritas. Desse modo, mesmo que a saída dos professores excedentes tenha sido involuntária, a escolha da unidade de destino pode expressar as preferências docentes, pois ao ter prioridade na escolha ele pode ter a possibilidade de ir para uma escola melhor.

É preciso salientar que o processo de decisão de deixar um posto de trabalho é complexo e influenciado por vários fatores específicos do indivíduo (como aspirações, preconceitos, satisfação profissional e pessoal, etc.), de sua família (filhos, problemas de saúde, etc.), do empregador (condições de trabalho, remuneração, etc.) e até conjunturais (facilidade de encontrar outro posto de trabalho, alternativas disponíveis). Assim, a decisão final - de trocar ou não de escola - resulta de uma ponderação de todos esses elementos.

Ademais, o perfil do alunado, o clima, a gestão, a vulnerabilidade da vizinhança, entre outros fatores, são correlacionados, de modo que, quando observamos um padrão de migração em que docentes saem de escolas com 
alunos mais pobres e vão para estabelecimentos com alunos de mais recursos socioculturais, isso não implica que os professores evitam conscientemente ou não o aluno com menos recursos. A escola que atende esse aluno pode acumular um conjunto de problemas que incentiva a saída de seus profissionais.

Após o deferimento da inscrição, os professores indicam, em ordem de preferência, as escolas para as quais desejam se remover. Essa indicação pode conter tantas escolas quanto o docente deseje e caso o candidato que se inscreveu de forma voluntária não indique nenhuma instituição, fica automaticamente excluído do concurso.

De acordo com dados da Secretaria Municipal de Educação, entre 10\% a 16\% do total de efetivos do EF1 se removeram nos anos compreendidos entre 2006 e 2011. Todavia, o volume de inscrições é três ou quatro vezes maior que o número de removidos, o que revela a concorrência acirrada entre os docentes. Neste universo, estudar as maneiras como as escolhas docentes se relacionam com as hierarquias socioespaciais depende do acesso a dados oficiais que, no contexto investigado, são publicados em Diário Oficial (DO). Primeiro são divulgadas as inscrições deferidas e indeferidas, depois a relação de vagas disponíveis e, em seguida, a classificação dos candidatos. Por fim, saem os resultados finais das remoções efetivadas, com as escolas de origem e de destino de cada candidato.

Essas informações foram usadas para a composição de um banco de dados em que foram registradas as entradas e saídas de professores no período de 2006 a 2011 relativas a cada uma das 23 escolas municipais localizadas na subprefeitura de São Miguel Paulista, bem como a classificação obtida por cada candidato. Assim, o primeiro recorte do estudo consistiu na delimitação geográfica das escolas.

As características da carreira docente no EF2 e no ensino médio também nos impeliram a realizar outro recorte em nossa amostra. Como os professores só podem trocar entre si as vagas que pertençam ao mesmo cargo que estão ocupando, a competição entre os professores habilitados para uma mesma disciplina do EF2 e/ou médio fornece um volume de dados menor, não permitindo a elaboração de conclusões mais consistentes na escala em que estamos trabalhando. Por isso, consideramos apenas dados relacionados aos professores de ensino fundamental I e, a partir de 2007, com a reestruturação na carreira do magistério municipal em São Paulo, dos professores dessa etapa e da educação infantil, uma vez que foi criado um cargo que reúne docentes das duas etapas. 


\section{OPÇÕES METOdOLÓgICAS E RESULtAdOS}

Além dos dados acerca dos concursos de remoção, foram utilizados dois indicadores: o Índice Paulista de Vulnerabilidade Social (IPVS) ${ }^{4}$ e o Índice de Heterogeneidade (IH). A caracterização do território foi feita a partir do IPVS, calculado pela Fundação Seade para todos os setores censitários do Estado de São Paulo. Esse indicador relaciona uma dimensão socioeconômica, formada pelos dados de renda e escolaridade do domicílio, e uma dimensão de ciclo de vida familiar (SÃO PAULO, 2004). Posteriormente, foi realizado o georreferenciamento das escolas municipais de ensino fundamental presentes na região de SMP.

A caracterização das escolas foi feita por duas variáveis. Para a mensuração dos níveis de vulnerabilidade social do entorno da escola, traçou-se um raio de $1 \mathrm{~km}$ a partir da escola e calculou-se a média do IPVS dos setores censitários localizados nessa área, gerando, para cada escola, um índice de vulnerabilidade de seu entorno: IPVS_ent. A partir desse índice e da classificação sugerida pela Fundação Seade, as escolas de São Miguel Paulista foram agrupadas em três faixas de IPVS_ent: vulnerabilidade baixa, média e alta.

A outra variável, o Índice de Heterogeneidade (IH), informa sobre a composição sociocultural do corpo discente comparando-o ao conjunto de todos os alunos da rede pública estadual e municipal de São Miguel Paulista. Os indicadores que dimensionam tais recursos vieram do questionário socioeconômico da Prova Brasil, a saber: a posse de TV, rádio, computador e internet; a quantidade de livros em casa; e o nível de escolaridade da mãe. Posteriormente, a distribuição dos alunos em cada escola em função dos seus recursos culturais foi comparada à distribuição total de alunos em SMP. O IH foi então classificado em três faixas: escolas homogêneas concentradoras de alunos com maiores recursos culturais; escolas heterogêneas; escolas homogêneas concentradoras de alunos com menores recursos culturais. A combinação IPVS_ent e IH dá origem a nove tipos de escolas, apresentados no infográfico a seguir:

4 Os dados do IPVS utilizados neste estudo foram construídos a partir do Censo de 2000. Até a conclusão da pesquisa ainda não haviam sido disponibilizados os dados de 2010. A comparação dos dados mostra algumas mudanças no território, que, no entanto, não invalidam os resultados aqui apresentados, ainda que possam ajudar na compreensão de algumas hipóteses. 


\section{Agrupamento das escolas de acordo com IPVS e IH}
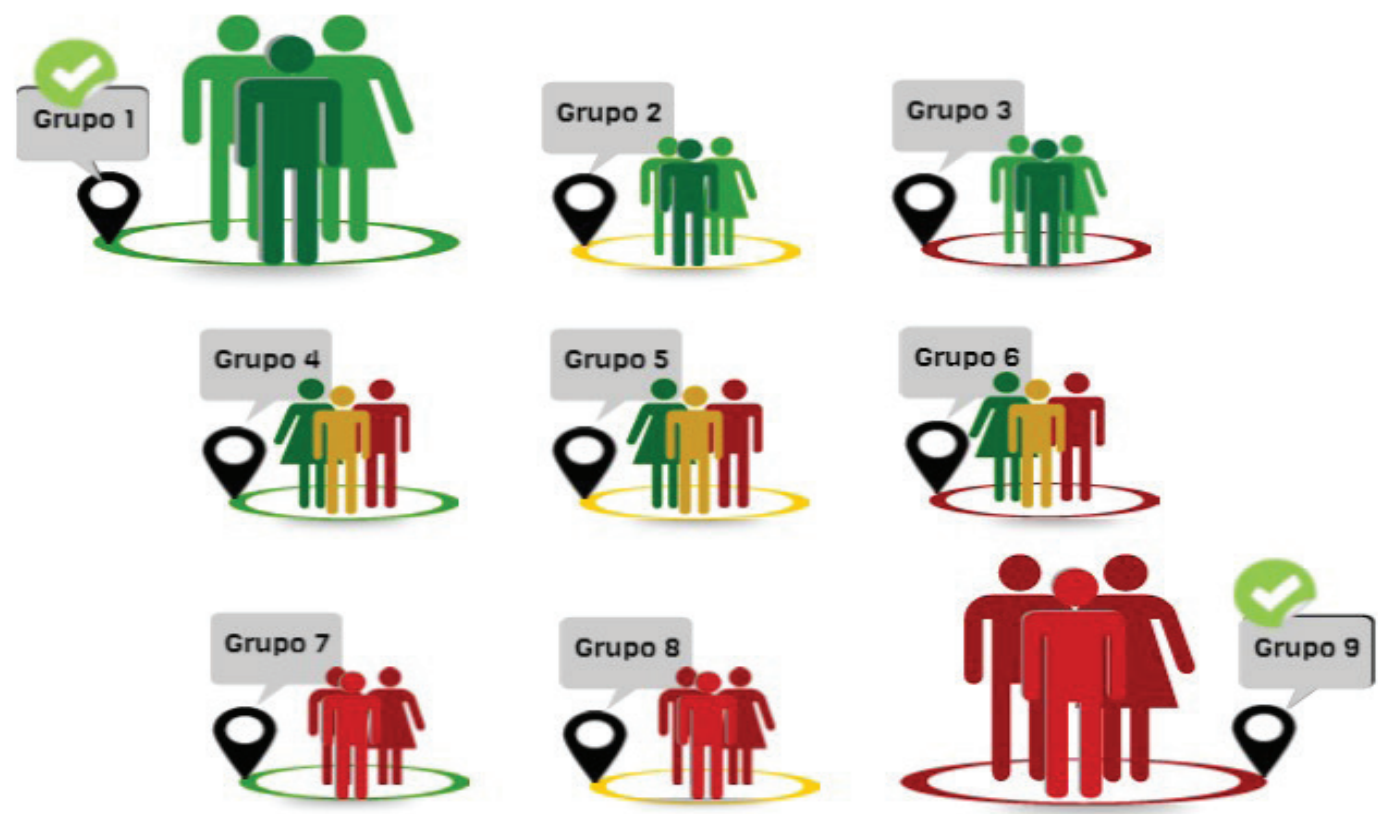

Figura 2: Agrupamento das escolas de acordo com o IPVS do entorno e o IH.

Fonte: Seade e Prova Brasil.

Os grupos 1 e 9 indicam as posições extremas. O grupo 1 permite a identificação das escolas nos territórios de baixa vulnerabilidade social e com corpo discente com maiores recursos culturais. 0 grupo 9, ao contrário, identifica as escolas situadas nos territórios de alta vulnerabilidade social e que concentram alunos com mais baixos recursos culturais. Em nossa amostra não há escolas que apresentassem os perfis ilustrados nos grupos 3 e 7.

Nossa hipótese inicial era que professores optariam por trabalhar em escolas do primeiro grupo ou de grupos adjacentes (grupos 2 e 4), ou seja, suas escolhas nos concursos de remoção se dariam, entre outros aspectos, em função das hierarquias socioespaciais, aqui representadas pelo IPVS, e da composição cultural do corpo discente $(\mathrm{IH})$, revelando uma relação entre a concorrência entre docentes e desigualdades socioespaciais.

Para que os dados dos diferentes anos do concurso pudessem ser trabalhados conjuntamente ${ }^{5}$, os professores foram classificados em função de sua posição

5 Trabalha-se com a hipótese de que as principais variáveis de interesse, o território e os 
no concurso. Se, no ano de 2006, mil professores participaram do concurso, aqueles posicionados entre os 25\% melhores receberam a classificação Q1, e assim por diante até o Q4, que agrega os de pior classificação. Feito isso para cada um dos anos considerados, os professores foram agregados por quartis e não mais por ano de participação no concurso.

É preciso salientar que as classificações em cada ano de concurso dependem do número de candidatos. O capital profissional é, portanto, relativo e um candidato cuja classificação o posicione no primeiro quartil em 2007 não necessariamente tem o mesmo capital profissional de um professor que ocupe quartil semelhante em 2011 ou em quaisquer outros dos anos ora considerados. O agrupamento em quartis não se refere, desse modo, a classificações semelhantes, mas sim a posições na carreira similares no momento do concurso de remoção.

O agrupamento em quartis nos permitiu analisar não apenas o número de removidos, mas a relação entre o capital profissional e as escolhas dos docentes, de modo que pudéssemos avançar no entendimento da tese de Becker relativa à ascensão socioespacial na carreira do magistério, verificando se os professores que ocupam as melhores posições nos concursos de remoção optam pelo ingresso em estabelecimentos de ensino que apresentam melhores condições nas variáveis que estamos considerando.

\subsection{A saída de professores da subprefeitura de SÃo Miguel Paulista}

Nossa amostra contém 523 remoções $^{6}$, cuja análise revela três tipos de escolha docente em relação à subprefeitura campo de nossa pesquisa: i) professores que saíram de uma das 23 escolas de SMP para outras subprefeituras (229);

recursos culturais dos alunos, permanecem mais ou menos constantes no período. No caso do território, como anteriormente assinalado, ainda que tenha havido mudanças durante o período, elas não invalidam o resultado e, como não há um indicador ano a ano, a opção pelo indicador do passado é mais lógica do que a do indicador do futuro. No caso do $\mathrm{IH}$, foi utilizada a média dos recursos culturais dos alunos dos anos de 2007 e 2009. Esses dois anos apresentam uma forte correlação entre o IH das escolas, indicando que não há uma mudança no perfil cultural no período que comprometa o uso dos dados agregados.

6 Aqui estamos considerando também professores que se removeram das 23 Emefs ou Emefems de São Miguel Paulista para Emeis. Nas análises que se baseiam em indicadores como IPVS e/ou IH, as trocas com as Emeis foram desconsideradas, pois não temos dados sobre a composição do alunado dessas escolas. 
ii) professores que entraram em uma das escolas de SMP vindos de outras subprefeituras (157); iii) professores que se removem dentre as 23 escolas de nossa amostra e que, portanto, se mantiveram em SMP (137).

Assim, as remoções revelam que a concorrência entre professores por escolas se expressa socioespacialmente em dois sentidos: um interno ao território e outro externo. 0 primeiro representa apenas $26 \%$ do total de remoções. Os $74 \%$ de remoções restantes se dão entre as 23 escolas de São Miguel e os demais estabelecimentos de ensino da cidade de São Paulo. A subprefeitura de SMP recebeu de outras regiões 157 professores e perdeu para elas 229, e isso pode estar também atrelado à queda das matrículas das escolas do território, conforme discutido na seção 2.

TABELA 1 - REMOÇÕES DE ESCOLAS DE SMP PARA OUTRAS SUBPREFEITURAS

\begin{tabular}{|l|c|c|c|}
\hline IPVS_ent & Saíram & Entraram & Saldo \\
\hline Baixa vulnerabilidade & 11 & 26 & 15 \\
\hline Média vulnerabilidade & 152 & 89 & -63 \\
\hline Alta vulnerabilidade & 66 & 42 & -24 \\
\hline Total & 229 & 157 & -72 \\
\hline
\end{tabular}

Fonte: Elaboração própria a partir de dados do Diário Oficial do município de São Paulo 2006-2011.

Na Tabela 1 constam as trocas de professores entre SMP e outras subprefeituras. Percebe-se que as escolas que perderam alunos são aquelas cujo entorno é mais vulnerável e que as escolas de baixa vulnerabilidade tiveram aumento do número de postos de trabalho. Apesar de não sabermos o motivo da queda de matrícula nas escolas analisadas, o fato de elas terem maior vulnerabilidade indica que essa perda de alunos pode se relacionar com o prestígio da escola - as famílias podem ter tirado seus filhos das escolas de média e alta vulnerabilidade, matriculando-os nas unidades menos vulneráveis. Para investigar tal hipótese é preciso estudar as movimentações discentes na cidade, exercício que faremos em pesquisa futura.

A análise das características dos docentes removidos revela que a subprefeitura de SMP perde mais professores do Q1 do que recebe e, por outro lado, ganha mais professores do Q4 do que perde. Ou seja, há uma tendência de perder os que ocupam as melhores posições e de ganhar os que ocupam as piores posições. Considerando apenas os $74 \%$ de professores que se removeram 
entre SMP e o restante da cidade, temos 154 docentes do quartil Q1, dos quais $67 \%$ optaram por sair de SMP e $33 \%$ optaram por ingressar na subprefeitura.

Em contrapartida, a análise do quartil Q4, ou dos professores de menor pontuação, mostra que 74 deles transitam entre SMP e São Paulo, sendo que 60\% chegam a SMP e 40\% saem. Essa situação pode sugerir também a dificuldade de saída daqueles que não acumularam capital profissional suficiente. Acredita-se ser possível, portanto, afirmar que essas são evidências que denotam uma tendência de que, enquanto os docentes removidos que possuem maior capital profissional vão trabalhar, em sua maioria, em outras subprefeituras, os professores de menor capital ocupam as vagas deixadas pelos primeiros.

Mesmo a subprefeitura apresentando uma atratividade limitada para muitos professores, alguns "escolhem" ingressar em escolas de SMP. As características desses docentes, bem como das escolas para as quais se removem, são analisadas no item que segue.

\subsection{Docentes Removidos de outras Regiões de SÃo Paulo para SMP}

Aqueles que ingressam em escolas de SMP não o fazem sem a observância das hierarquias socioespaciais e socioculturais. As análises relacionadas ao perfil das escolas revelam que quanto maior a vulnerabilidade do entorno de uma escola e a concentração de alunos com mais baixos recursos culturais, maiores as chances de que ela receba professores de pior classificação no concurso de remoção. Isso pode ser mais bem analisado na Figura 3, que contrapõe as três variáveis ora consideradas (IH, IPVS_ent e quartil de classificação do capital profissional dos professores que se removeram). O gráfico foi dividido em nove partes a partir de faixas consideradas altas, médias e baixas para os índices em questão, sendo: escolas com entorno de alta vulnerabilidade aquelas com IPVS maior que 3,6; entorno de baixa vulnerabilidade, IPVS menor que 3,0 e vulnerabilidade média as escolas com IPVS entre esses valores. Paralelamente, escolas com um IH maior que 0,1 foram consideradas como de concentração de alunos com maiores recursos culturais; IH menor que $-0,1$, de concentração de alunos com menores recursos culturais; e médias as com $\mathrm{IH}$ entre -0,1 e 0,1. As partes do gráfico correspondem aos tipos descritos na Figura 1.

A parte superior e à esquerda do segundo quadrante indica escolas com um entorno de baixa vulnerabilidade e de concentração de alunos com 
maiores recursos culturais. A parte inferior do quarto quadrante indica a situação contrária, ou seja, escolas com entorno de alta vulnerabilidade e de concentração de alunos com mais baixos recursos culturais.

escolas que receberam a maioria dos professores do Q1

escolas que receberam a maioria dos professores do Q2 e Q3

$\Delta$ escolas que receberam a maioria dos professores do Q4

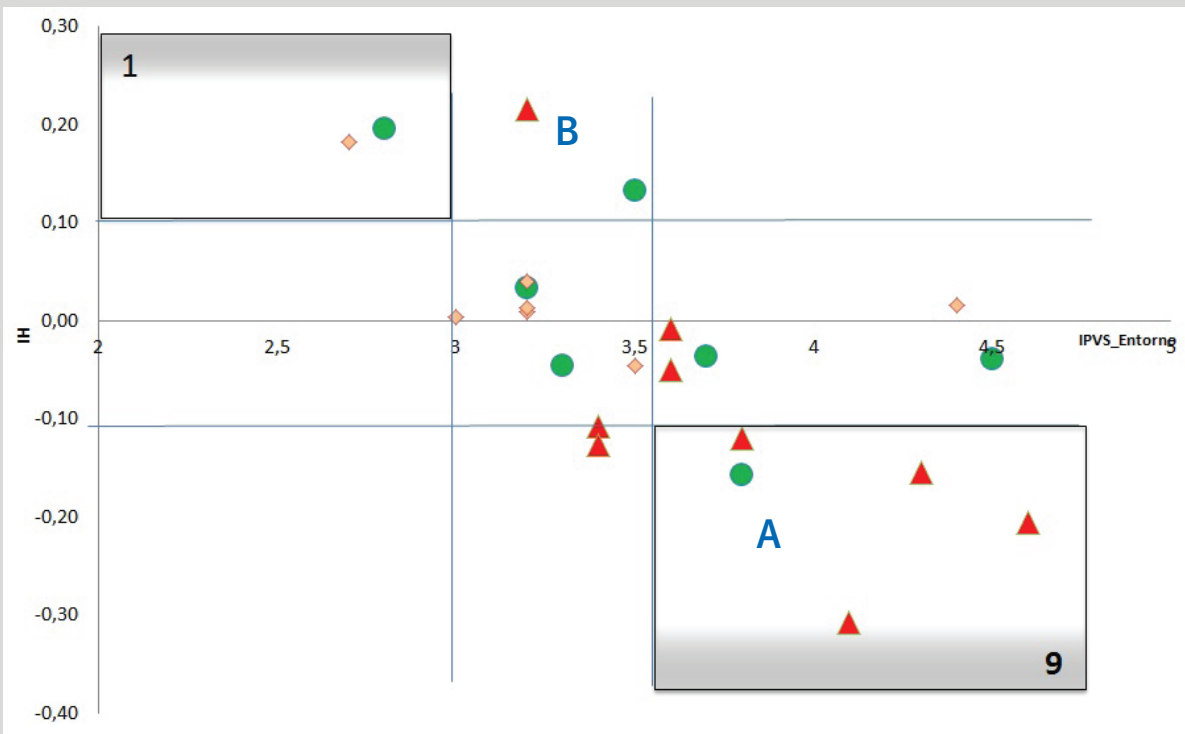

Figura 3: Classificação das escolas e perfil de professores nos concursos de remoção.

Fonte: Elaboração própria a partir de dados do Inep, Fundação Seade e Diário Oficial.

Vê-se que quatro das nove escolas que receberam a maioria dos professores do Q4 (de menor pontuação nos concursos de remoção) do gráfico está na parte 9, corroborando nossas conclusões anteriores. No entanto, há algumas exceções, como uma escola verde na parte 9 do gráfico - escola A - e uma escola vermelha na parte 2 - escola $B$.

Investigamos qualitativamente as exceções apontadas na Figura 3 para compreender que outros fatores condicionam a atratividade das escolas. Obtivemos boa parte das informações aqui descritas por meio de conversas com a equipe gestora das escolas - através de telefonemas - e outras nos foram fornecidas por supervisores de ensino da Diretoria Regional de Ensino de São Miguel Paulista, na ocasião em que apresentamos a eles os resultados parciais deste estudo.

A única escola posicionada na parte 9 do gráfico (escola A; Ideb 2011 4,7), que recebeu professores de maior capital profissional, apresenta características diferentes da maioria das escolas de nossa amostra: foi inaugurada recentemente (em 2009), está próxima a uma rodovia que liga São Paulo a 
Guarulhos e possui estacionamento para professores. Segundo a diretora e alguns supervisores, esses fatores atraem professores que i) acumulam cargo, pois numa escola recém-inaugurada as hierarquias de escolha de turmas e turnos ainda estão em formação, oferecendo maiores oportunidades para docentes que precisam escolher determinado horário de trabalho ou preferem determinadas turmas; ii) residem em municípios vizinhos e precisam trafegar pela rodovia que liga São Paulo a esses municípios; iii) preocupam-se em deixar seus carros em segurança enquanto lecionam ou em ter segurança na hora de sair ou entrar em seus carros.

A análise dos padrões de remoção da escola A revela uma relação curiosa com o estabelecimento B (Ideb 2011 5,2), este posicionado na parte 2 do gráfico

e, portanto, situado num entorno de vulnerabilidade média e concentrador de alunos com maiores recursos culturais, mas que recebeu ao longo dos anos considerados neste trabalho uma maioria de professores do Q4. Em 2009, a escola B "perdeu" seis professores, sendo que cinco deles se dirigiram para a escola $A$, sua vizinha, o que sugere uma relação de concorrência entre esses estabelecimentos para a atração e manutenção dos docentes.

O intercâmbio de professores entre SMP e a cidade revela, com algumas exceções, a existência de um padrão interno de diferenciação entre escolas que se apoia na desigualdade socioespacial do território e na composição sociocultural do alunado, e que interfere na concorrência entre docentes por postos de trabalho disponíveis em áreas que apresentem melhores condições sociais.

\subsection{AS TROCAS INTRATERRITÓRIO}

Como há remoções que são realizadas entre escolas da subprefeitura, levantamos a hipótese de que o intercâmbio intraterritório revela, de modo mais intenso que as demais trocas, um mecanismo de ascensão socioespacial na carreira docente, tal como proposto por Becker (1952), pois temos condições de conhecer as características dos estabelecimentos "abandonados" e dos escolhidos pelos docentes.

A Tabela 2 resume as movimentações de docentes efetivos entre as escolas de SMP. Nota-se que a maioria dos docentes que trabalhava em estabelecimentos com entorno de média ou alta vulnerabilidade, concentrando alunos de baixos recursos culturais ou de recursos heterogêneos, migrou para escolas 
“melhores”, corroborando nossa hipótese de que a remoção de professores sinaliza a possibilidade de ascensão socioespacial na carreira docente, no contexto investigado.

Nos dois grupos citados, analisados conjuntamente, 64\% dos docentes removidos ascenderam socioespacialmente: escolheram escolas de perfil melhor que o apresentado por suas escolas de origem. Outros $23 \%$ permanecem em escolas com perfil semelhante e 13\% apresentaram decesso, ou seja, foram para escolas de perfil pior do que aquele verificado nos estabelecimentos de ensino do qual provinham.

TAbela 2 - Remoção de professores dentro da subprefeitura de São Miguel Paulista

\begin{tabular}{|c|c|c|c|c|c|}
\hline \multirow{2}{*}{$\begin{array}{l}\text { Característica } \\
\text { da escola }\end{array}$} & \multicolumn{2}{|c|}{ Saída } & \multicolumn{3}{|c|}{ Entrada } \\
\hline & $\begin{array}{l}\text { Número de } \\
\text { professores }\end{array}$ & $\%$ & $\begin{array}{l}\text { Situação } \\
\text { socioespacial }\end{array}$ & $\begin{array}{l}\text { Número de } \\
\text { professores }\end{array}$ & $\%$ \\
\hline \multirow{3}{*}{$\begin{array}{c}\text { IH alto } \\
\text { IPVS baixo }\end{array}$} & \multirow{3}{*}{19} & \multirow{3}{*}{$13,9 \%$} & Ascende & 0 & $0,0 \%$ \\
\hline & & & Permanece & 3 & $15,8 \%$ \\
\hline & & & Cai & 16 & $84,2 \%$ \\
\hline \multirow{3}{*}{$\begin{array}{l}\text { IH médio } \\
\text { IPVS médio }\end{array}$} & \multirow{3}{*}{54} & \multirow{3}{*}{$39,4 \%$} & Ascende & 24 & $44,4 \%$ \\
\hline & & & Permanece & 15 & $27,8 \%$ \\
\hline & & & Cai & 15 & $27,8 \%$ \\
\hline \multirow{3}{*}{ IH baixo } & \multirow{3}{*}{64} & \multirow{3}{*}{$46,7 \%$} & Ascende & 52 & $81,2 \%$ \\
\hline & & & Permanece & 12 & $18,8 \%$ \\
\hline & & & Cai & 0 & $0,0 \%$ \\
\hline
\end{tabular}

Fonte: Elaboração própria a partir de dados do Inep, Fundação Seade e Diário Oficial.

Esse mecanismo de ascensão horizontal pode ser mais bem observado quando isolamos as trocas de professores efetivadas entre os dois grupos extremos de nossa pesquisa: escolas de melhor perfil social e territorial e escolas em condições opostas, onde nesses grupos ${ }^{7}$ temos, respectivamente, duas e cinco escolas. Como é possível observar abaixo, enquanto dois professores optam por deixar as duas escolas de melhor perfil apresentando uma trajetória descendente, 22 professores deixam escolas do grupo 9 e ascendem socioespacialmente.

$7 \quad$ Ver grupos 1 e 9 na Figura 2. 
O desenho da rede de trocas entre docentes oferece elementos para analisar como se estrutura, para o caso investigado, a rede de interdependência. Essas redes são comumente elaboradas em função da movimentação de alunos entre escolas (ver, por exemplo, YAIR, 1996, BARTHON; MONFROY, 2005), mas nossos dados demonstram que elas podem também ser descritas a partir das transferências entre docentes, o que intentamos fazer em pesquisa futura.

Para que essa rede seja traçada, será preciso considerar um aspecto que não pudemos verificar neste trabalho: a estrutura de vagas existentes no território, pois a ascensão só é possibilitada, obviamente, pela desocupação ou criação de vagas mais prestigiadas. Levando em conta as análises mais gerais feitas ao longo deste trabalho, uma desocupação se daria em três sentidos: a migração para outras subprefeituras, a migração/remoção de docentes para escolas do próprio território e a saída do professor da rede (por motivo de aposentadoria, exoneração, abandono da profissão, etc.). Assim, para entender a fundo a hipótese da ascensão socioespacial é necessário mapear a estrutura de vagas existentes na rede.

\section{CONSIDERAÇÕES FINAIS}

Este texto apresenta pesquisa que investigou um dos mecanismos pelos quais desigualdades socioespaciais interferem no funcionamento de escolas que se situam em territórios vulneráveis - a influência de tais desigualdades sobre a alocação de professores em escolas municipais de São Miguel Paulista. Os resultados apontam que a vulnerabilidade do território em que está situada a escola e a composição sociocultural do corpo discente influenciam a mobilidade docente.

A combinação das regras de remoção em vigor na cidade de São Paulo e, possivelmente, de uma hierarquia das escolas construída pelos professores, conforme apontada pela literatura, resulta em dificuldades para manter e atrair professores em escolas de bairros de alta vulnerabilidade. 0 padrão de migração dos docentes se dá em direção a escolas de entornos menos vulneráveis e com público de maiores recursos sociais e culturais.

A discussão feita neste informe sugere que a concorrência entre professores, organizada pelas regras dos concursos de remoção, agrava as desigualdades educacionais que se expressam territorialmente, haja vista a saída de professores mais bem posicionados na carreira e a atração daqueles de pior posição 
para as escolas de SMP. Analisar como o capital profissional dos docentes impacta a oferta educacional nos territórios não foi o objetivo deste estudo, mas, a partir da relação entre atratividade da escola e desempenho dos alunos elaborada por outros estudos, há indícios de que escolas menos atrativas para os docentes são também aquelas que apresentam os piores resultados. 0 estudo revela a necessidade de novas pesquisas que permitam analisar os impactos da alocação de docentes para a equidade do sistema educacional.

Os dados apresentados também fornecem pistas para a compreensão de como a remoção se configura como um dos aspectos que estruturam a interdependência entre estabelecimentos de ensino (VAN ZANTEN, 2005; BARTHON; MONFROY, 2005), já que as boas condições de funcionamento de uma escola, em se tratando do preenchimento do quadro de professores, se constroem a partir da descapitalização de outras instituições, notadamente aquelas situadas em áreas vulneráveis. Nesse sentido, o contexto de nossa investigação indica que essa interdependência se assenta, entre outros fatores, nas desigualdades socioespaciais que marcam a metrópole paulistana.

É necessário frisar que o processo de decisão do professor de deixar uma escola é complexo, subjetivo e influenciado por vários fatores específicos do indivíduo, de sua família, do empregador e até conjunturais. Por conseguinte, a decisão final - de trocar ou não de escola - resulta de uma ponderação de todos esses elementos.

Ademais, o perfil do alunado, o clima, a gestão, a vulnerabilidade da vizinhança, entre outros fatores, são correlacionados, de modo que, quando observamos um padrão de migração em que docentes saem de escolas com alunos com menos recursos socioculturais e vão para estabelecimentos com alunos de mais recursos socioculturais, isso não implica que os professores evitam consciente ou inconscientemente o aluno de baixo capital sociocultural. Além dos elementos apontados no parágrafo anterior, a escola que atende esse aluno pode acumular um conjunto de problemas que incentiva a saída de seus profissionais.

Apesar dos limites desta pesquisa, já mencionados no texto, pode-se afirmar que seus resultados deixam entrever vínculos entre desigualdades socioespaciais (vistas por meio de indicadores de vulnerabilidade social das escolas e das regiões de São Paulo), desigualdades sociais (indicadas pelos níveis de recursos socioculturais dos alunos) e interdependência competitiva entre escolas (devido à vantagem de algumas escolas em detrimento de outras da mesma rede de ensino, na captação de professores com maior capital profissional) em uma região considerada mais vulnerável. 


\title{
Teachers' transfer and inequalities in vulnerable areas
}

\begin{abstract}
The article investigates one of the mechanisms by which socio-spatial inequalities interfere with schools operating in vulnerable areas, in this case concerning teacher allocation in municipal schools in the district of São Miguel Paulista (SMP), São Paulo. In order to verify the supposition that teachers as a rule migrate to schools in less vulnerable neighborhoods at which students have more social and cultural resources, we have analysed data of transfer applications from 2006 to 2011 for teachers working in Elementary School first years, available in the City of São Paulo official newspaper. Results show that schools located in less vulnerable areas and concentrating more resourceful students attract teachers who have achieved better positions in their career. Schools with opposite characteristics get less successful teachers.
\end{abstract}

Keywords: Teachers’s transfer. Social vulnerability. Area. 
BARTHON, Catherine; MONFROY, Brigitte. Les espaces locaux d'interdépendance entre collèges: l'exemple de La ville de Lille. Espace, Populations, Societés, Paris, v. 3, p. 385-396, 2005.

BECKER, Howard S. The career of the Chicago public school teacher. American Journal of Sociology, v. 57, n. 5, p. 470-477, mar. 1952.

BIONDI, Roberta Loboda; FELÍCIO, Fabiana de. Atributos escolares e o desempenho dos estudantes: uma análise em painel dos dados do Saeb. Brasília, 2007. Disponivel em: 〈http://www.oei.es/pdfs/atributos_escolares_desempeno_ brasil.pdf〉. Acesso em: 8 abr. 2013.

CLOTFELTER, Charles; LADD, Helen F.; VIGDOR, Jacob L. Teacher mobility, school segregation, and pay-based policies level the playing field. Education Finance and Policy, v. 6, n. 3, p. 399-438, summer 2011.

DELVAUX, Bernard. Méthode de définition des espaces d'interdépendance entre écoles. Les Cahiers du Cerisis, n. 24, p. 1-45, jan. 2005.

ÉRNICA, Mauricio; BATISTA, Antônio A. G. A escola, a metrópole e a vizinhança vulnerável. Cadernos de Pesquisa, São Paulo, v. 24, n. 146, p. 640-666, maio/ ago. 2012. Disponível em: 〈http://www.scielo.br/pdf/cp/v42n146/16.pdf〉. Acesso em: 6 maio 2013.

HANUSHEK, Eric A. et al. Why public school lose teachers. The Journal of Human Resources, v. 39, n. 2, p. 326-354, spring 2004.

The market for teacher quality. NBER Working Paper n. 11154, 2005. Disponivel em: 〈http://www.nber.org/papers/w11154〉. Acesso em: 27 maio 2013.

HANUSHEK, Eric A.; RIVKIN, Steven G. Teacher quality. In: HANUSHEK, Eric A.; WELCH, FINIS (ED.). Handbook of the economics of education. v. 2. Amsterdã: North Holland, 2006. 742 p.

KASMIRSKI, Paula Reis. Mobilidade de professores na rede estadual paulista. 2012. Dissertação (Mestrado em Teoria Econômica)-Programa de Pós-Graduação em Economia, Departamento de Economia, Faculdade de Economia e Administração e Contabilidade, Universidade de São Paulo, São Paulo, 2012.

MICRODADOS da Prova Brasil 2007. Base de dados. Instituto Nacional de Estudos e Pesquisas Educacionais Anísio Teixeira (Inep). Disponível em: 〈http://portal.inep. gov.br/basica-levantamentos-acessar». Acesso em: 8 abr. 2013.

MORDUCHOWICZ, Alejandro. Carreiras, incentivos e estruturas salariais docentes. Série Preal documentos, n. 23, jun. 2003. Disponível em: 〈http://www.oei.es/ docentes/articulos/carreras_incentivos_estructuras_salariales_docentes_ morduchowicz_portugues.pdf〉. Acesso em: 8 abr. 2013. 
Pfeffer, Jeffrey; Salancik Gerald R. The external control of organizations. New York: Harper and Row Publishers, 1978.

RONFELDT, Matthew et al. How teacher turnover harms student achievement. Working Paper 17176, National Bureau of Economic Research, 2011. Disponivel em: 〈http://www.nber.org/papers/w17176〉. Acesso em: 5 maio 2012.

SÃO PAULO. Fundação Seade. IPVS: índice paulista de vulnerabilidade social. 2004. Disponível em: 〈http://www.seade.gov.br/projetos/ipvs/〉. 2004. Acesso em: $1^{0}$ set. 2011.

SÃO PAULO (Município). Edital de Abertura de Inscrições e de Procedimentos dos Concursos de Remoção 2011 dos profissionais de educação e de titulares de cargos de diretor de equipamento social, auxiliar de desenvolvimento infantil e especialista em informações técnicas, culturais e desportivas. Diário Oficial da Cidade de São Paulo: Poder Executivo. São Paulo, SP, 2011.

. Lei no 11.229, de 26/06/1992. Diário Oficial da Cidade de São Paulo: Poder Executivo. São Paulo, SP, 1992.

. Decreto no 49.796, de 22/07/2008. Diário Oficial da Cidade de São Paulo: Poder Executivo. São Paulo, SP, 2008. . Lei no 14.660, de 16/12/2007. Diário Oficial da Cidade de São Paulo: Poder Executivo. São Paulo, SP, 2007.

TORRES, Haroldo da Gama et al. Educação na periferia de São Paulo: ou como pensar as desigualdades educacionais? In: RIBEIRO, Luiz Cesar de Queiroz; KAZTMAN, Ruben (Org.). A cidade contra a escola: segregação urbana e desigualdades educacionais em grandes cidades da América Latina. Rio de Janeiro: Letra Capital, Faperj, Ippes, 2008.

VAN ZANTEN, Agnès. Efeitos da concorrência sobre as atividades dos estabelecimentos de ensino. Cadernos de Pesquisa, São Paulo, v. 35, n. 126, p. 565-593, set./dez., 2005.

; GROSPIRON, Marie-France. Les carrières enseignantes dans les établissements difficiles: fuite, adaptation et développement professionnel. VEI Enjeux, n. 124, p. 71-93, mars 2001.

YAIR, Gad. School organization and market ecology: a realist sociological look at the infrastructure of school choice. British Journal of Sociology of Education, v. 17, n. 4, p. 453-471, 1996.

RECEBIDO: Abril de 2015.

APROVADO: Maio de 2015. 
